\title{
Bexarotene-Induced Hypertriglyceridemia: A Case Report
}

\author{
Chris Maminakis $^{\mathrm{a}}$ Arin C. Whitman ${ }^{\mathrm{b}}$ Nahida Islam ${ }^{\mathrm{b}}$ \\ aCollege of Pharmacy and Health Sciences, Western New England University, \\ Springfield, MA, USA; ${ }^{b}$ Oncology Clinic, UMass Memorial Medical Center, \\ Worcester, MA, USA
}

\section{Keywords}

Bexarotene $\cdot$ Cutaneous T-cell lymphoma $\cdot$ Hypertriglyceridemia

\section{Abstract}

We present a case of a patient with cutaneous T-cell lymphoma started on bexarotene 300 $\mathrm{mg} / \mathrm{m}^{2}$ due to progressing disease. The patient experienced good clinical response, but unfortunately, she developed rapid and profound hypertriglyceridemia. Although hypertriglyceridemia occurs in high incidence with bexarotene therapy, management recommendations are scarce. Due to the rise in triglycerides, atorvastatin $10 \mathrm{mg}$ daily was initiated in combination with fenofibrate $120 \mathrm{mg}$ daily. Triglycerides continued to increase, so the patient was instructed to take atorvastatin $40 \mathrm{mg}$, fenofibrate $120 \mathrm{mg}$, and to hold bexarotene for 2 weeks. After the 2-week break, bexarotene was restarted at $150 \mathrm{mg} / \mathrm{m}^{2}$.

\author{
(C) 2018 The Author(s) \\ Published by S. Karger AG, Basel
}




\section{Case Reports in Oncology}

Case Rep Oncol 2018;11:234-238

DOI: 10.1159/000488447

(c) 2018 The Author(s). Published by S. Karger AG, Base www.karger.com/cro

Maminakis et al.: Bexarotene-Induced Hypertriglyceridemia: A Case Report

\section{Introduction}

Bexarotene induces significant lipid abnormalities in most patients (increased triglycerides and total cholesterol and decreased high-density lipoprotein) within the first 2-4 weeks [1]. The fasting lipid panel should be monitored at baseline, followed weekly until response to bexarotene is determined/stabilized, and then checked every 8 weeks [1]. Recommendations from the manufacturer are to reduce the dose, discontinue, and/or add antilipemic therapy [1]. In studies, HMG-CoA reductase inhibitors were used to manage lipids; gemfibrozil is not recommended due to its potential for drug interactions [2].

\section{Case Report}

The patient was a 69-year-old female diagnosed with T2 N0 stage IB versus T2 N1 stage IIA cutaneous T-cell lymphoma diagnosed in July 2015. Imaging at this time showed cervical lymphadenopathy up to $1.5 \mathrm{~cm}$, but no biopsies were obtained. With limited nodular skin lesions on the back of her neck, scalp, and trunk, she was originally treated with narrowband ultraviolet B phototherapy and topical steroids. In November of 2017, a new nodular skin biopsy showed progressive disease (stage IIB disease), and systemic therapy was discussed. Upon physical examination, a nodular rash on her neck, scalp, trunk, and extremities was the only abnormality. At the time, the patient was on the following medications: Acetaminophen $500 \mathrm{mg}$ every $6 \mathrm{~h}$ as needed for pain, betamethasone $0.05 \%$ lotion as directed, diphenhydramine $25 \mathrm{mg}$ as directed, hydrochlorothiazide $25 \mathrm{mg}$ daily, hydroxyzine $10 \mathrm{mg}$ daily, ketoconazole $2 \%$ shampoo as directed, triamcinolone acetonide $0.1 \%$ cream as directed, and a daily multivitamin. Bexarotene was started on November 29, 2017, at $300 \mathrm{mg} / \mathrm{m}^{2}$ (body surface area $1.81 \mathrm{mg} / \mathrm{m}^{2}$ ) upon recommendation from Radiation Oncology. The baseline lipid panel was within normal limits.

Two weeks after bexarotene therapy initiation; triglycerides were at $639 \mathrm{mg} / \mathrm{dL}$, with total cholesterol at $208 \mathrm{mg} / \mathrm{dL}$ and high-density lipoprotein (HDL) at $18 \mathrm{mg} / \mathrm{dL}$. Atorvastatin $20 \mathrm{mg}$ daily was added to the patient's regimen after this initial lipid panel had been obtained on December 13, 2017. Triglycerides continued to rise for the next 2 weeks $(1,067$ $\mathrm{mg} / \mathrm{dL}$ on December 20 and 1,202 mg/dL on December 27). Fenofibrate $120 \mathrm{mg}$ daily was added, and atorvastatin increased to $80 \mathrm{mg}$ daily on January 3, 2018. Bexarotene therapy was stopped on January 19, 2018, due to the rapid rise of triglycerides (peaked at 1,507 $\mathrm{mg} / \mathrm{dL}$ on January 17,2018 ) with no response to lipid-lowering therapy. Just 5 days after halting bexarotene, her triglycerides decreased to $520 \mathrm{mg} / \mathrm{dL}$, with total cholesterol at 294 $\mathrm{mg} / \mathrm{dL}$ and HDL at $13 \mathrm{mg} / \mathrm{dL}$.

Bexarotene was held for 2 weeks, but lipid-lowering therapy was continued throughout this "drug holiday" in hopes that it will begin to take effect. On January 31, 2018, triglycerides decreased to $144 \mathrm{mg} / \mathrm{dL}$, with total cholesterol at $196 \mathrm{mg} / \mathrm{dL}$ and HDL at $43 \mathrm{mg} / \mathrm{dL}$. Bexarotene was restarted at $150 \mathrm{mg} / \mathrm{m}^{2}$. Over the course of 2 weeks, triglycerides increased to $575 \mathrm{mg} / \mathrm{dL}$ and HDL decreased to $8 \mathrm{mg} / \mathrm{dL}$. The rise in lipids was not as dramatic as in the previous bexarotene trial, and the trend has since plateaued (Table 1). If the lipid panel worsens, therapy must be discontinued. The patient has had a very good clinical response to 


\section{Case Reports in Oncology}

Case Rep Oncol 2018;11:234-238

DOI: $10.1159 / 000488447$

(c)

2018 The Author(s). Published by S. Karger AG, Base www.karger.com/cro

Maminakis et al.: Bexarotene-Induced Hypertriglyceridemia: A Case Report

bexarotene, as her skin rash has almost completely resolved. Her palpable lymphadenopathy has also resolved.

\section{Discussion}

Bexarotene is commonly classified as a rexinoid due to its selective activity at retinoid X receptors (RXRs) [3]. It can be used systemically in patients with cutaneous T-cell lymphoma, specifically when patients have extensive plaques and tumors refractory to skin-directed therapy [4]. It can also be given topically in patients with less severe and localized disease. The most common side effect noted is hypertriglyceridemia, which has been reported in up to $\sim 80 \%$ of the patients [3]. There are no established guidelines for the prevention and management of bexarotene-induced hypertriglyceridemia, and most resources will just encourage cessation of therapy.

The mechanism of the side effect is still poorly understood, but one logical hypothesis has been made in which RXRs and liver X receptors (LXRs) can form a permissive heterodimer that can lead to increased plasma triglyceride levels [5]. RXRs are unique nuclear receptors that can modulate transcription by forming homo- or heterodimers with other nuclear receptors such as LXRs [5]. This heterodimer formation is believed to be the only way that LXRs can increase plasma triglycerides, and this is only done when the RXR portion of the heterodimer is agonized [5]. Hypertriglyceridemia is recognized as an independent risk factor for cardiovascular disease, and the unnatural rapid onset of this hypertriglyceridemia that can occur (particularly in this case) is an extra cause for concern. Little to no research has been found to identify cardiovascular risk in the setting of bexarotene-induced hypertriglyceridemia.

Although a lack of management recommendations was previously mentioned, a UK consensus statement in the British Journal of Dermatology contained very detailed recommendations [2]. Prior to therapy, a low-fat diet should be counseled, along with a decrease in alcohol and vitamin A intake (the latter due to retinoid activation) [2]. Fenofibrate should be started well ahead of therapy regardless of lipid profile due to the 2-3 months it could take to determine clinical efficacy (at least 1-2 weeks prior to initiation of therapy) [2]. Statins should also be considered in combination. Bexarotene is metabolized by CYP3A4 (low-level interaction with atorvastatin), so rosuvastatin is the preferred statin in this situation [5]. The combination of fenofibrate and a statin can increase the risk of myalgia, so following creatine kinase levels may be beneficial [2]. During therapy, starting at $150 \mathrm{mg} / \mathrm{m}^{2}$ may be helpful, even if it is only half the labeled dose for this type of cancer [2]. Titrating up by $75 \mathrm{mg}$ every 2-4 weeks may help ease the patient into therapy, but the medication should be stopped if triglycerides exceed $1,000 \mathrm{mg} / \mathrm{dL}$ [2]. If the fibrate-statin combination therapy is not producing enough lipid-lowering effect, niacin and/or ezetimibe can be considered [2]. However, this would further increase the risk of myalgia. The patient should be familiar with the risk, and creatine kinase labs should be checked if this option is chosen [2]. It is important to note that ezetimibe only decreases lipids absorbed from diet, and the mechanism behind bexarotene-induced hypertriglyceridemia is not well enough understood to confirm that ezetimibe can be efficacious in this scenario. Fish oil can be considered, as it is usually mentioned in the setting of hypertriglyceridemia. 
Although most cancers are not considered immediate and emergent conditions, withholding treatment just to wait for lipid-lowering therapy to kick in will likely not go over well with any cancer patient, especially a newly diagnosed patients. In this case particularly, it took approximately 1 month and a half for the patient's triglyceride levels to triple (at the least - the first lipid panel was taken 2 weeks after initiation). To add to that phenomenon, it took just 5 days after therapy cessation to return down around to where it started. Lipidlowering therapy may not have had any effect on this patient. Fibrates and statins need weeks to months to determine clinical efficacy, and that time frame was not able to be properly identified. Given that the patient has now been on atorvastatin and fenofibrate for over 1 month, restarting at half-dose and titrating up may produce more favorable results in terms of reducing this prevalent adverse effect.

In conclusion, bexarotene-induced hypertriglyceridemia is a legitimate concern in all patients initiating therapy with bexarotene, regardless of a history of elevated triglycerides. Proactivity in the management of this adverse effect due to the high prevalence may limit the extent of the elevation in lipids and may provide enough benefit to safely continue bexarotene therapy.

\section{Statement of Ethics}

The authors have no ethical conflicts to declare. Patient consent was received.

\section{Disclosure Statement}

The authors have no conflicts of interest to disclose.

\section{References}

1 Targretin [package insert]. Bridgewater (NJ): Valeant Pharmaceuticals North America LLC; 2015 [cited 2018 Feb 27]. Available from: https://www.accessdata.fda.gov/drugsatfda_docs/label/2015/021055s010lbl.pdf.

2 Scarisbrick JJ, Morris S, Azurdia R, Illidge T, Parry E, Graham-Brown R et al. U.K. consensus statement on safe clinical prescribing of bexarotene for patients with cutaneous T-cell lymphoma. Br J Dermatol. 2013 Jan;168(1):192-200.

3 Quéreux G, Saint-Jean M, Peuvrel L, Brocard A, Knol AC, Dréno B. Bexarotene in cutaneous T-cell lymphoma: third retrospective study of long-term cohort and review of the literature. Expert Opin Pharmacother. 2013 Sep;14(13):1711-21.

4 Willemze R, Hodak E, Zinzani PL et al. Primary Cutaneous Lymphoma: ESMO Clinical Practice Guidelines. Ann Oncol. 2013;24 Suppl 6:vi149-54.

5 Lalloyer F, Pedersen TA, Gross B, Lestavel S, Yous S, Vallez E et al. Rexinoid bexarotene modulates triglyceride but not cholesterol metabolism via gene-specific permissivity of the RXR/LXR heterodimer in the liver. Arterioscler Thromb Vasc Biol. 2009 Oct;29(10):1488-95. 


\section{Case Reports in Oncology}

Case Rep Oncol 2018;11:234-238

DOI: $10.1159 / 000488447$

(c)

(c) 2018 The Author(s). Published by S. Karger AG, Basel www.karger.com/cro

Maminakis et al.: Bexarotene-Induced Hypertriglyceridemia: A Case Report

Table 1. Patient fasting lipid panels

\begin{tabular}{|c|c|c|c|c|c|c|c|c|c|c|c|c|}
\hline & $12 / 13$ & $12 / 20$ & $12 / 27$ & $1 / 3$ & $1 / 17$ & $1 / 24$ & $1 / 31$ & $2 / 7$ & $2 / 14$ & $2 / 21$ & $2 / 28$ & $3 / 6$ \\
\hline Total cholesterol, mg/dL & 208 & 235 & 262 & 341 & 280 & 294 & 196 & 169 & 173 & 221 & 191 & 225 \\
\hline Triglycerides, mg/dL & 639 & 1,067 & 1,202 & 1,332 & 1,507 & 520 & 144 & 347 & 575 & 555 & 439 & 539 \\
\hline High-density lipoprotein, mg/dL & 18 & 8 & 8 & 15 & 9 & 13 & 43 & 26 & 8 & 9 & 9 & 15 \\
\hline
\end{tabular}

